\title{
Medium and feed optimization for fed-batch production of a monoclonal antibody in $\mathrm{CHO}$ cells
}

\author{
Nadine Kochanowski, Gaetan Siriez, Sarah Roosens, Laetitia Malphettes \\ From 22nd European Society for Animal Cell Technology (ESACT) Meeting on Cell Based Technologies \\ Vienna, Austria. 15-18 May 2011
}

\section{Background}

Mammalian cells are used extensively in the production of recombinant proteins, and of monoclonal antibodies (MAbs) in particular. The trend towards avoiding animal-derived components in biopharmaceutical production processes has led to the extensive use of nonanimal origin hydrolysates such as plant hydrolysates or yeast hydrolysates. The source of hydrolysates affects cell growth and productivity and may also affect product quality. Accordingly, careful consideration should be given during process and cell culture media development, in order to determine the appropriate type and amount of hydrolysates to be added, for the cell and product at hand.

In this study, we assessed the impact of several hydrolysate additives and chemically defined (CD) commercial feeds on MAb titers, MAb average specific productivity (average Qp), cell viabilities and metabolite profiles in suspension cultures of recombinant $\mathrm{CHO}$ cells expressing a monoclonal antibody in shake flasks and $2 \mathrm{~L}$ bioreactors.

\section{Materials and methods}

Initial experiments were performed using chemically defined culture medium in $125 \mathrm{~mL}$ shake flasks with 50 $\mathrm{mL}$ working volume. $\mathrm{CHO}$ cells were seeded at $0.3 \times 10^{6}$ viable cells $/ \mathrm{mL}$ and incubated at $140 \mathrm{rpm}, 36.5^{\circ} \mathrm{C}$ and $5 \% \mathrm{CO}_{2}$. 2L stirred tank bioreactors (Sartorius) were carried out for 14 days in a fed-batch mode in a chemically defined medium supplemented with chemically defined feeds and hydrolysates. Glucose was maintained

\footnotetext{
* Correspondence: Nadine.Kochanowski@ucb.com

Cell Culture Process Development Group, Biological Process Development,

UCB Pharma S.A., Braine L'Alleud, 1420, Belgium

Full list of author information is available at the end of the article
}

between 1 and $6 \mathrm{~g} / \mathrm{L}$. At the day of harvest the clarification was performed by depth filtration. Analysis of daily samples included determinations of cell viability, cell density, metabolites, osmolality and product titer. Product concentration of the supernatant samples was quantified using Octet QK and Protein A high performance liquid chromatography (HPLC). Protein characterization of Protein-A purified samples were profiled by reduced and non reduced SDS PAGE. Isoelectric focusing (IEF) analysis of Protein-A purified MAb was carried out using a iCE280 IEF Analyzer. Aggregates and monomers proportion were determined by using size exclusion chromatography. Acidic and basic species were characterized using anion exchange (AEX) HPLC. Oligosaccharides were cleaved enzymatically using N-Glycanase, then labeled with 2-aminobenzamide and analyzed by HPLC using an amide column and a fluorescent detector.

\section{Results}

Several chemically defined feeds and hydrolysates were assessed on $\mathrm{CHO}$ cells expressing a monoclonal antibody in fed-batch mode. The performance of the developed process was compared to an existing in-house platform process.

Nine different chemically defined feeds were assessed and added at different concentrations (Table 1). Among the feeds tested, addition of CD Feed 8 and 9 brought a $150 \%$ improvement on MAb titer on the day of harvest compared to the platform process. All the MAb titers measured were ranging from $2 \mathrm{~g} / \mathrm{L}$ to $6 \mathrm{~g} / \mathrm{L}$ (Figure 1).

Six different hydrolysates were assessed at different concentrations in fed-batch mode (Table 1). Among the feeds tested, addition of hydrolysate 1 and hydrolysate 2 
Table 1 Chemically defined feeds and hydrolysates tested

\begin{tabular}{|c|c|c|}
\hline Supplier & Commercial feed name & Feed name in the poster \\
\hline ThermoFischer & Cell Boost 1 & CD Feed 1 \\
\hline ThermoFisher & Cell Boost 2 & CD Feed 2 \\
\hline ThermoFisher & Cell Boost 3 & CD feed 3 \\
\hline ThermoFischer & Cell Boost 4 & CD Feed 4 \\
\hline ThermoFischer & Cell Boost 5 & CD Feed 5 \\
\hline ThermoFischer & Cell Boost 6 & CD Feed 6 \\
\hline Life Tech & $\mathrm{CHO}$ Feed $\mathrm{A}$ & CD Feed 7 \\
\hline Life Tech & $\mathrm{CHO}$ Feed B & CD Feed 8 \\
\hline Life Tech & CHO Feed C & CD Feed 9 \\
\hline BD Biosciences & Yeast Extract & Hydrolysate 1 \\
\hline BD Biosciences & Yeastolate & Hydrolysate 2 \\
\hline BD Biosciences & Select Phytone & Hydrolysate 3 \\
\hline BD Biosciences & Ultrapep Soy & Hydrolysate 4 \\
\hline Sheffield & HyPep 1510 & Hydrolysate 5 \\
\hline Sheffield & HyPep 4605 & Hydrolysate 6 \\
\hline BD Biosciences & $3 \mathrm{~g} / \mathrm{L}$ Yeast Extract $+3.25 \mathrm{~g} / \mathrm{L}$ Yeastolate & Hydrolysate combination 1 \\
\hline BD Biosciences & $3.5 \mathrm{~g} / \mathrm{L}$ Yeast Extract $+2.75 \mathrm{~g} / \mathrm{L}$ Yeastolate & Hydrolysate combination 2 \\
\hline BD Biosciences & $4 \mathrm{~g} / \mathrm{L}$ Yeast Extract $+2.25 \mathrm{~g} / \mathrm{L}$ Yeastolate & Hydrolysate combination 3 \\
\hline BD Biosciences & $4.5 \mathrm{~g} / \mathrm{L}$ Yeast Extract $+1.75 \mathrm{~g} / \mathrm{L}$ Yeastolate & Hydrolysate combination 4 \\
\hline BD Biosciences & $5 \mathrm{~g} / \mathrm{L}$ Yeast Extract $+1.25 \mathrm{~g} / \mathrm{L}$ Yeastolate & Hydrolysate combination 5 \\
\hline BD Biosciences & $3 \mathrm{~g} / \mathrm{L}$ Yeast Extract $+5.1 \mathrm{~g} / \mathrm{L}$ Yeastolate & Hydrolysate combination 6 \\
\hline BD Biosciences & $3.5 \mathrm{~g} / \mathrm{L}$ Yeast Extract $+4.6 \mathrm{~g} / \mathrm{L}$ Yeastolate & Hydrolysate combination 7 \\
\hline BD Biosciences & $4 \mathrm{~g} / \mathrm{L}$ Yeast Extract $+4.1 \mathrm{~g} / \mathrm{L}$ Yeastolate & Hydrolysate combination 8 \\
\hline BD Biosciences & $4.5 \mathrm{~g} / \mathrm{L}$ Yeast Extract $+3.6 \mathrm{~g} / \mathrm{L}$ Yeastolate & Hydrolysate combination 9 \\
\hline BD Biosciences & $5 \mathrm{~g} / \mathrm{L}$ Yeast Extract $+3.1 \mathrm{~g} / \mathrm{L}$ Yeastolate & Hydrolysate combination 10 \\
\hline
\end{tabular}

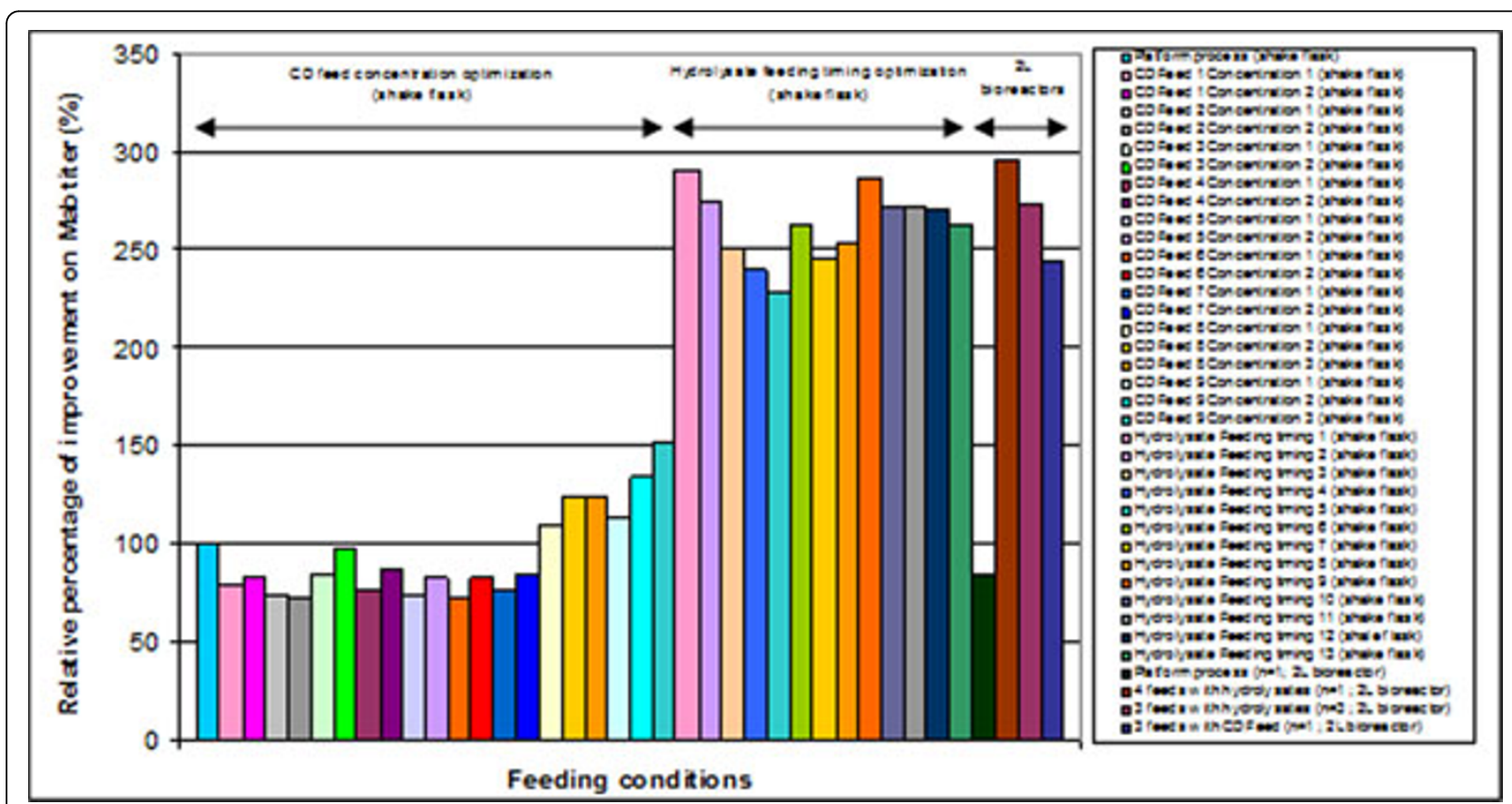

Figure 1 Relative percentage of improvement on MAb titer. Note: Platform process in shake flask was used as the 100\% reference for all the calculations of relative percentage of improvement on Mab titer measured the day of harvest 
showed an improvement of $175 \%$ and $167 \%$ respectively on MAb yield.

To identify potential synergies between hydrolysates, the best hydrolysates from previous experiments were selected and were tested in combination at different ratios on CHO cell cultures (Table 1). Antibody concentration at harvest was $290 \%$ higher with some of the hydrolysate combinations.

Based on feed combination optimization results, the number of bolus feeds and the feed addition timing were then fine-tuned using the best hydrolysate combination. Reducing the number of bolus feeds enabled to reduce ammonia and osmolality while maintaining a high MAb titer (Figure 1). Moreover, under these conditions, cell viabilities were maintained above $80 \%$ throughout the culture (data not shown).

Based on experimental results obtained in shake flasks, the best hydrolysate combination ( 3 feeds and 4 feeds) and $\mathrm{CD}$ feed were assessed on $\mathrm{CHO}$ cells cultured in 2 $\mathrm{L}$ stirred tank bioreactors. Cell growth and cell metabolism were monitored daily throughout the cultures in bioreactors. By feeding the cultures with hydrolysates, addition of 3 or 4 bolus feeds enabled to attain similar maximum viable cell count. Addition of chemically defined feed led to a $30 \%$ higher maximum viable cell count. Cell viabilities were maintained at acceptable values throughout the cultures in the established culture conditions. Lactate profiles were similar independently of the feeding regime. Decreasing the number of hydrolysate feeds enabled to maintain osmolality and ammonia at acceptable concentrations for $\mathrm{CHO}$ cell growth and product quality. Cell growth performance and metabolism profiles observed in $2 \mathrm{~L}$ bioreactors were comparable to those observed in shake flasks.

Product titers have been measured throughout the fed-batch cultures with the Octet QK system. The MAb titers were in a 2-6 g/L range for all the tested feeding regimes at the day of harvest. A combination of hydrolysates and a chemically defined feed supplementation showed an improvement of $296 \%$ and $245 \%$ on MAb concentration at the day of harvest in comparison to the platform process (Figure 1). MAb average specific productivity $(\mathrm{Qp})$ was increased by $700 \%$ and $360 \%$ by adding 4 feeds of hydrolysates and chemically defined feed respectively. Decreasing the number of hydrolysate feeds showed a slight decrease on MAb titer and on Qp.

Product quality attributes were determined on cell culture clarified fluids after Protein-A purification. Reduced and non reduced SDS electrophoresis, isoelectric focusing (IEF) analysis, gel permeation HPLC, size exclusion (SEC) chromatography, anion exchange HPLC (AEX) have been used to characterize the Protein-A purified MAb. Product quality data was comparable for all the feeding regimes tested in $2 \mathrm{~L}$ bioreactors.

\section{Conclusions}

Hydrolysate combination additions significantly improved MAb production in comparison to single hydrolysate addition or chemically defined feeds. Number of bolus feeds and feeding timing optimization enabled us to improve the process robustness taking into account the impact of feeding strategy on cell metabolism and product quality. The feeding regimes established in shake flasks led to similar culture performance in $2 \mathrm{~L}$ bioreactors.

\section{Acknowledgments}

We wish to acknowledge BD Biosciences, Sheffield, Life Tech and Thermofisher for providing media and feeds. We also wish to acknowledge Mari Spitali, Natasha Hinkel, Vanessa Auquier and Marc Speleers for Protein-A purification and product quality analysis.

Published: 22 November 2011

doi:10.1186/1753-6561-5-S8-P75

Cite this article as: Kochanowski et al.: Medium and feed optimization for fed-batch production of a monoclonal antibody in $\mathrm{CHO}$ cells. BMC Proceedings 2011 5(Suppl 8):P75.
Submit your next manuscript to BioMed Central and take full advantage of:

- Convenient online submission

- Thorough peer review

- No space constraints or color figure charges

- Immediate publication on acceptance

- Inclusion in PubMed, CAS, Scopus and Google Scholar

- Research which is freely available for redistribution

Submit your manuscript at www.biomedcentral.com/submit
( Biomed Central 